\title{
Suppression of microRNA-18a expression inhibits invasion and promotes apoptosis of human trophoblast cells by targeting the estrogen receptor $\alpha$ gene
}

\author{
XIAOMING ZHU ${ }^{1,2 *}$, YANG YANG ${ }^{3 *}$, TAO HAN $^{4 *}$, GUOWU YIN ${ }^{2 *}$, PING GAO $^{2 *}$, \\ YUNFENG NI $^{5 *}$, XIAOHUA SU ${ }^{2}$, YUYING LIU ${ }^{2}$ and YUANQING YAO ${ }^{2}$
}

${ }^{1}$ Department of Obstetrics and Gynecology, Tangdu Hospital, Fourth Military Medical University, Xi'an, Shanxi 710038;
${ }^{2}$ Department of Obstetrics and Gynecology, General Hospital of Chinese People's Liberation Army, Beijing 100853;
${ }^{3}$ Department of Obstetrics and Gynecology, Affiliated Hospital of Xi'an Medical University, Xi'an, Shanxi 710077;
${ }^{4}$ Department of Orthopedics, Hainan Branch of PLA General Hospital, Sanya, Hainan 572013; ${ }^{5}$ Department of
Thoracic Surgery, Tangdu Hospital, Fourth Military Medical University, Xi'an, Shanxi 710038, P.R. China

Received July 1, 2014; Accepted February 3, 2015

DOI: $10.3892 / \mathrm{mmr} .2015 .3724$

\begin{abstract}
The purpose of the present study was to gain further understanding of the function of microRNA-18a (miR-18a) expression in the JEG-3 human trophoblast cell line. JEG-3 cells were transfected with pre-miR-18a mimics or miR-18a inhibitors. The effects of miR-18a on trophoblast cell invasion and apoptosis, and on the expression of estrogen receptor $\alpha$ $(\mathrm{ESR} \alpha)$ were analyzed using a Transwell invasion assay, flow cytometry, reverse transcription-polymerase chain reaction, western blot analysis and a luciferase assay. The results of the present study suggested that miR-18a expression suppression led to a decrease in JEG-3 cell invasion and an increase in JEG-3 cell apoptosis, by inducing ESR $\alpha$ expression. The present study provides evidence for the involvement of miR-18a in the pathogenesis of pre-eclamptic pregnancies.
\end{abstract}

\section{Introduction}

MicroRNAs (miRs) are a class of small (21-24 bp), noncoding RNAs, which are involved in the negative regulation of gene expression. miRs bind to complementary sequences in the

Correspondence to: Dr Xiaoming Zhu, Department of Obstetrics and Gynecology, Tangdu Hospital, Fourth Military Medical University, 569 Xinsi Street, Xi'an, Shanxi 710038, P.R. China

E-mail: xiaomingzhu1981@hotmail.com

Dr Yuanqing Yao, Department of Obstetrics and Gynecology, General Hospital of Chinese People's Liberation Army, 28 Fuxing Street, Beijing 100853, P.R. China

E-mail: rao_yu_zxm@hotmail.com

*Contributed equally

Key words: microRNA-18a, estrogen receptor $\alpha$, JEG-3 cell, invasion, apoptosis 3'-untranslated region (3'-UTR) of their target mRNAs, causing destabilization of the transcript or inhibition of translation (1-3). miRs are involved in a number of biological and pathological processes, including cell proliferation, cell differentiation and carcinogenesis $(4,5)$. Previous studies have suggested that $\mathrm{miR}$ expression is tissue-specific and that a number of miRs are expressed in the human placenta $(6,7)$. A previous study demonstrated that miR-18a is downregulated in pre-eclamptic placentas (8). miR-18a is a component of the miR-17-92 gene cluster, which is located on chromosome 13q31.3. Evidence has suggested that miR-18a targets the estrogen receptor $\alpha-3^{\prime}$ (ESR $\left.\alpha-3^{\prime}\right)$ UTR in human hepatocellular carcinoma cells (9).

ESRs are ligand-activated transcription factors. They are members of the nuclear hormone receptor superfamily, which mediate the pleiotropic effects of the steroid hormone, estrogen via a range of developmental and physiological processes (10). There are two forms of ESR: ESR $\alpha$ and ESR $\beta$, which are encoded by ESR1 and ESR2, respectively. ESR $\alpha$ is predominantly expressed in the ovaries, uterus and placenta (11), while ESR $\beta$ is expressed in a number of types of tissues (12). A previous study suggested that ESR $\alpha$ mRNA and protein levels were significantly increased in pre-eclamptic pregnancies compared with levels in healthy pregnancies (13).

Previous studies have demonstrated that miR-18a is underexpressed (8), and ESR $\alpha$ is overexpressed, in pre-eclamptic placentas (13). The results of previous studies have suggested that miR-18a may be involved in the pathogenesis of pre-eclamptic pregnancies via $\mathrm{ESR} \alpha$ regulation. In order to gain further understanding of the association between miR-18a and ESR $\alpha$ in human trophoblast cells, the present study analyzed the effect of miR-18a on trophoblast invasion, cell apoptosis and ESR $\alpha$ expression in JEG-3 cells.

\section{Materials and methods}

Cell culture and transient transfection. JEG-3 human trophoblast choriocarcinoma cells were obtained from the American Type Culture Collection (ATCC, Manassas, VA, 
Table I. Primer sequences and reaction conditions for reverse transcription-polymerase chain reaction.

\begin{tabular}{|c|c|c|c|}
\hline Gene & Primer sequences & Annealing temperature $\left({ }^{\circ} \mathrm{C}\right)$ & Cycle (n) \\
\hline $\mathrm{ESR} \alpha$ & $\begin{array}{l}\text { F: CCTGGCTAGAGATCCTGAT } \\
\text { R: CCCTGGTTCCTGTCCAAGA }\end{array}$ & 56 & 31 \\
\hline$\beta$-actin & $\begin{array}{l}\text { F: TCATCACTATTGGCAACGAGC } \\
\text { R: AACAGTCCGCCTAGAAGCAC }\end{array}$ & 55 & 25 \\
\hline miR-18a & $\begin{array}{l}\text { RT: GTCGTATCCAGTGCAGGGTCCGAG } \\
\text { GTATTCGCACTGGATACGACTATCTG } \\
\text { F: GTGCTAAGGTGCATCTAGTGCAG } \\
\text { R: GTGCAGGGTCCGAGGT }\end{array}$ & 50 & 30 \\
\hline U6 & $\begin{array}{l}\text { RT: AACGCTTCACGAATTTGCGT } \\
\text { F: CTCGCTTCGGCAGCACA } \\
\text { R: AACGCTTCACGAATTTGCGT }\end{array}$ & 55 & 29 \\
\hline
\end{tabular}

RT-PCR, reverse-transcription polymerase chain reaction; F, forward; R, reverse; miR, microRNA; ESR $\alpha$, estrogen receptor $\alpha$.

USA). JEG-3 cells were cultured in Dulbecco's modified Eagle's medium (DMEM; Gibco Life Technologies, Carlsbad, CA, USA), containing $10 \%$ fetal bovine serum (FBS; Gibco Life Technologies, Carlsbad, CA, USA). Cells were cultured at $37^{\circ} \mathrm{C}$, in a humidified atmosphere at $5 \% \mathrm{CO}_{2}$.

Pre-miR-18a mimics (pre-miR-18a), pre-miR negative control (NC), an miR-18a inhibitor and miR-18a inhibitor FAM-labeled controls were used to determine the transfection efficiency and were purchased from Jima (Beijing, China). JEG-3 cells were transfected with pre-miR-18a or miR-18a inhibitors using Lipofectamine $2000{ }^{\circledR}$ (Gibco Life Technologies) according to the manufacturer's instructions. The medium was replaced with fresh growth medium following $12 \mathrm{~h}$ of transfection. Following 48-72 h of transfection, a Transwell invasion assay was conducted.

Transwell invasion assay. Transfected cells were seeded at $4 \times 10^{5}$ cells/insert in Transwell inserts $(8-\mu \mathrm{m}$ pore size; Costar, Corning, Cambridge, MA, USA) pre-coated with BD matrigel matrix (BD Biosciences, USA), and they were incubated with DMEM medium, without FBS. Lower chambers were loaded with DMEM medium, containing $10 \%$ FBS.

Cells were incubated at $37^{\circ} \mathrm{C}$ for $24 \mathrm{~h}$. Following incubation, invading cells were fixed with $95 \%$ ethanol and stained using crystal violet (Beyotime Institue of Biotechnology, Nanjing, China). Non-invading cells were removed with a cotton swab. The cell invasion index was determined by counting the number of stained cells in ten randomly selected non-overlapping fields of the membranes, using a light microscope (TE2000S; Nikon, Japan; magnification, x200).

Cell apoptosis assay via flow cytometry. Following transfection for $48 \mathrm{~h}$, JEG-3 cell apoptosis was analyzed using flow cytometry. $5 \times 10^{5}$ treated cells/well were seeded into 24 -well plates and were incubated with annexin $\mathrm{V}$ and propidium iodide (BD Biosciences, San Diego, CA, USA) for $15 \mathrm{~min}$ at room temperature, in darkness. Cells were then analyzed using a fluorescence activated cell sorting (FACS) flow cytometer (BD Biosciences). Experiments were repeated three times.
Reverse transcription-polymerase chain reaction (RT-PCR) analysis. Total RNA was isolated from JEG-3 cells using TRIzol $^{\circledR}$ (Invitrogen Life Technologies, Carlsbad, CA, USA). RNA integrity was confirmed using electrophoresis in a $1.5 \%$ agarose denaturing gel (Sangon Biotech, Shanghai, China). In order to detect the presence of $\mathrm{ESR} \alpha, 1 \mu \mathrm{g}$ total RNA was reverse transcribed into cDNA and primed with oligonucleotides, using a RevertAid first-strand cDNA synthesis kit (Thermo Fisher Scientific Baltics, Vilnius, Lithuania). $\beta$-Actin was used as a positive control.

In order to detect the miR, $2 \mu \mathrm{g}$ of total RNA was reverse transcribed into cDNA with a gene-specific RT primer, which is capable of folding into a stem-loop structure. The highly conserved and universally expressed small nuclear RNA, U6, was used as an endogenous control. Primer sequences and PCR conditions are provided in Table I. A $25-\mu 1$ PCR master mix was prepared as follows: RT products $(1 \mu \mathrm{l})$, dNTPs $(200 \mu \mathrm{mol} / \mathrm{l})$, $\mathrm{MgCl}_{2}(2 \mathrm{mmol} / \mathrm{l})$, Taq DNA polymerase (1 IU)and primers (10 pmol).

PCR amplification was verified within the exponential phase of PCR using preliminary experiments. PCR products were subjected to electrophoresis on agarose gels, and the relative densities of target genes, standardized against that of the control genes was analyzed, using Image-Pro Plus (version 6.0; Media Cybernetics, Inc., Rockville, MD, USA).

Western blot analysis. Infected cells were washed three times with ice-cold phosphate-buffered saline (PBS) and then lysed with $1 \mathrm{X}$ lysis buffer (Cell Signaling Technology, Inc., Danvers, MA, USA). The supernatant was collected following centrifugation at $12,000 \mathrm{x}$ g for $10 \mathrm{~min}$ at $4{ }^{\circ} \mathrm{C}$ and protein estimation was conducted using a Bradford assay (14). Protein (30 $\mu \mathrm{g})$ per lane was separated using $10 \%$ SDS-polyacry1-amide gel electrophoresis and transferred onto a polyvinylidene fluoride membrane (Hybond; GE Healthcare, Chalfont, UK) via semidry electroblotting. The membrane was blocked in 5\% non-fat milk in PBS with Tween-20 ${ }^{\circledR}$ (PBST) for $1 \mathrm{~h}$ at room temperature, and incubated with rabbit antibodies against human $\operatorname{ESR} \alpha(1: 2,500$; 
A

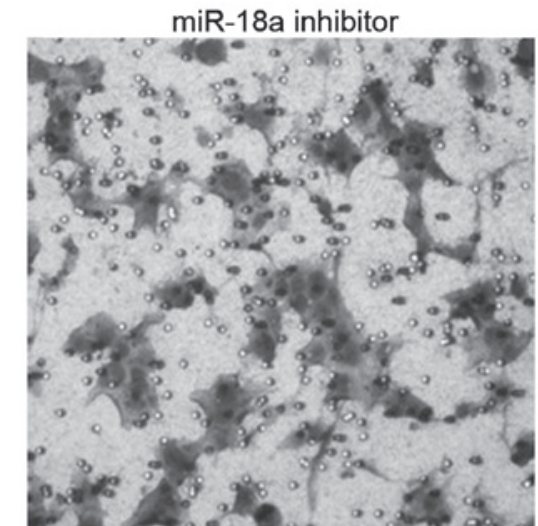

miR-18a inhibitor FAM control

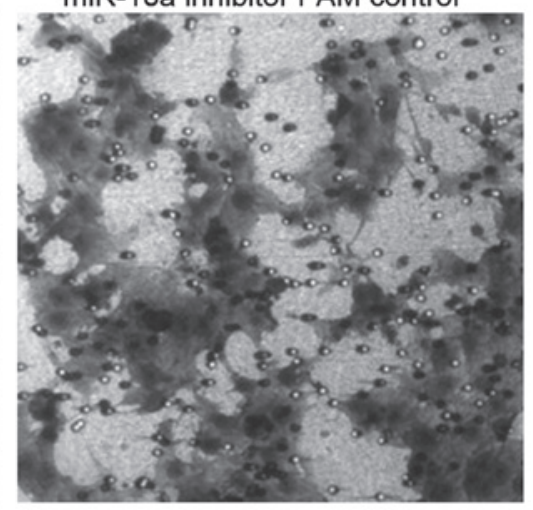

B
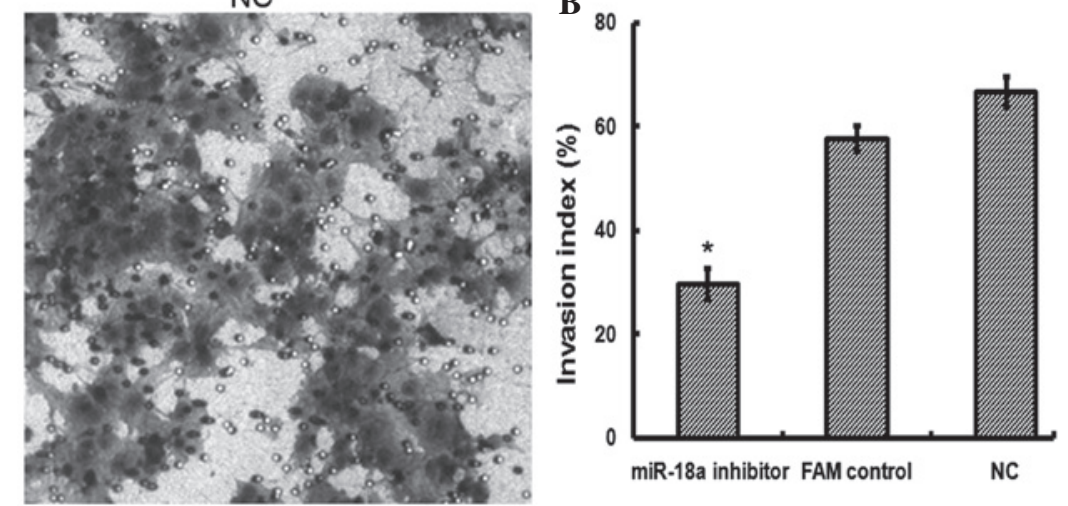

Figure 1. Suppression of miR-18a expression inhibits JEG-3 cell invasion. (A) Invasion assay of JEG-3 cells transfected with an miR-18a inhibitor, miR-18a inhibitor FAM control or NC. The cells were stained with crystal violet and observed by microscopy (magnification, x200). (B) Densitometric analysis of invasion assay. Values represent the mean \pm standard deviation of three independent experiments. ${ }^{*} \mathrm{P}<0.05$ vs. FAM control and NC. miR, microRNA, NC, pre-miR-18a negative control.

rabbit monolonal; cat. no. ab32063; Epitomics, Burlingame, $\mathrm{CA}, \mathrm{USA})$, in PBS at $4^{\circ} \mathrm{C}$ overnight.

The membrane was washed PBST and incubated with a horseradish peroxidase-conjugated secondary antibody (1:5,000; cat. no. cw0111; Kangwei, Beijing, China) for $1 \mathrm{~h}$ at room temperature. Expression signals were detected using the Enhanced Chemiluminescent Substrate (Pierce Biotechnology, Inc., Rockford, IL, USA). The membrane was stripped and reprobed with the rabbit-anti-human $\beta$-actin antibody (1:3,000; Abcam, Cambridge, UK), which was used as a positive control. ESR $\alpha$ expression was standardized against that of $\beta$-actin, which was determined using densitometric analysis (Image-Pro Plus 6.0; Media Cybernetics, Inc., Rockville, MD, USA).

Luciferase reporter assay. In order to perform a luciferase reporter assay, the 3'-UTR segment of ESR $\alpha$, which contains the miR-18a binding site (NM_000125), was PCR amplified using the total RNA extracted from JEG-3 cells and the following primers for ESR $\alpha$ : Forward: 5'-CCTAGCTAGCCAATGACCCAGGTGAGCTGCTCG-3' and reverse: 5'-CCTAGCTAGCCATTCAATTGTCT GATAAACAAGC-3' (9). The reporter plasmid was cloned by inserting the 3'-UTR segment of ESR $\alpha$ into the $X b a$ I site of a pGL3-Promoter vector (Promega Corporation, Madison, WI, USA), in order to generate pMIR-UTR. The mutant ESR $\alpha-3$-UTR fragment was generated using a QuickChange II Site-Directed Mutagenesis kit (Agilent Technologies, Inc.,
Santa Clara, CA, USA). Transfection was performed using a Lipofectamine 2000 reagent.

Transfections of JEG-3 cells were performed using pMIR-UTR and pre-miR-18a for the experimental group. For the negative control group, transfections were performed using pMIR-UTR and pre-miR-control. Transfections were performed with pMIR-UTR-mutant and pre-miR-18a, for the mutant control group. Following $48 \mathrm{~h}$ of transfection, cells were lysed and measured for luciferase activity using a luciferase assay system (Promega Corporation, Madison, WI, USA), according to the manufacturer's instructions. Cells were also transfected with $50 \mathrm{ng}$ pRL-TK vector as an internal standard.

Statistical analysis. Values are presented as the mean \pm standard deviation of three individual experiments. Comparisons between groups were performed using one-way analysis of variance. In all cases $\mathrm{P}<0.05$ was considered to indicate a statistically significant difference. Statistical analyses were performed using SPSS version 13.0 (SPSS, Inc., Chicago, IL, USA).

\section{Results}

Suppression of miR-18a expression inhibits JEG-3 cell invasion. A cell invasion assay was performed in order to investigate the effect of miR-18a on JEG-3 cell invasion. As shown in Fig. 1, the suppression of miR-18a significantly inhibited cell invasion in JEG-3 cells $(29.67 \pm 3.06$; $\mathrm{P}<0.05)$ compared 
A
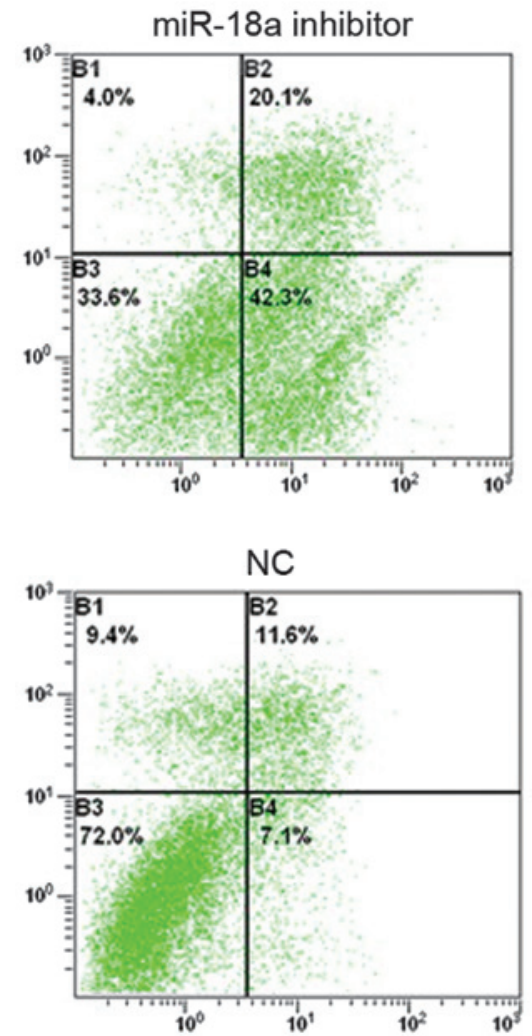

miR-18a inhibitor FAM control
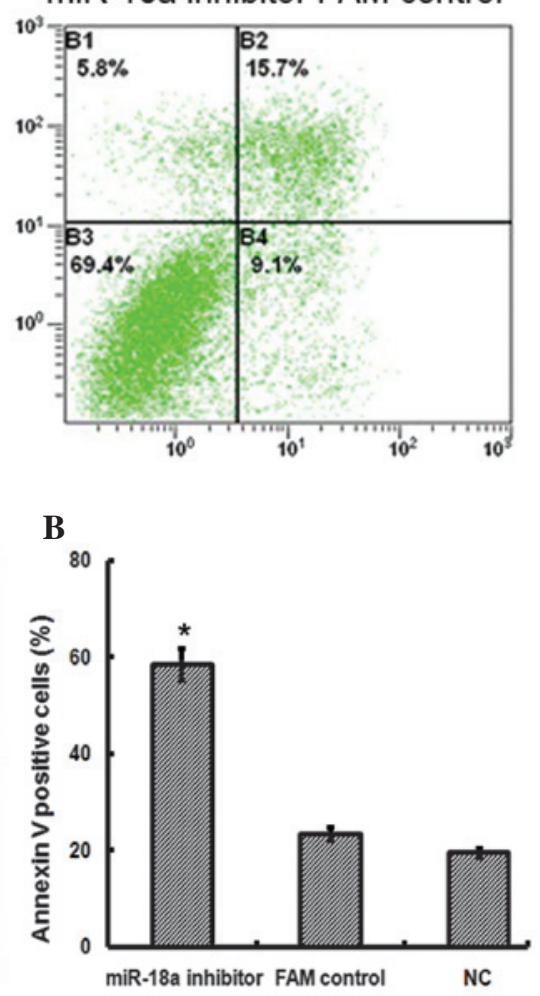

Figure 2. Suppression of miR-18a leads to increased JEG-3 cell apoptosis. (A) Cell apoptosis assay of JEG-3 cells, transfected with miR-18a inhibitor, miR-18a inhibitor FAM control or NC. (B) Densitometric analysis of cell apoptosis assay. Values are presented as the mean \pm standard deviation of three independent experiments. " $\mathrm{P}<0.05$ vs. controls. miR, microRNA; ESR $\alpha$, estrogen receptor $\alpha$; NC, negative control; B1, necrotic cells; B2, late apoptotic cells; B3, normal cells; B4, early apoptotic cells.

with that in the NC and FAM control cells $(66.67 \pm 3.06$ and $57.67 \pm 2.52$, respectively). The data suggested that suppression of miR-18a may inhibit the invasive capacity of JEG-3 cells.

Suppression of miR-18a leads to increased cell apoptosis in $J E G-3$ cells. A cell apoptosis assay was performed using flow cytometry, in order to investigate whether decreased miR-18a expression in JEG-3 cells was associated with a change in cell apoptosis. Following transfection with the miR-18a inhibitor, JEG-3 cell apoptosis was higher $(58.63 \pm 3.27$; $\mathrm{P}<0.05)$ than

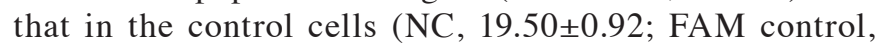
23.30 \pm 1.37 ; Fig. 2). The results of the present study, therefore, suggested that the suppression of miR-18a expression may promote JEG-3 cell apoptosis.

Validation of ESR $\alpha$ as a target of miR-18a in JEG-3 cells. In order to assess whether miR-18a affects ESR $\alpha$ expression, the levels of ESR $\alpha$ mRNA and protein were measured in JEG-3 cells that had been transfected with pre-miR-18a or miR-18a inhibitor. RT-PCR analysis suggested that transfection was effective (Fig. 3A). Significant differences were observed in ESR $\alpha$ mRNA expression levels: Pre-miR-18a, 0.25 \pm 0.01 ; NC, $0.32 \pm 0.01$; miR-18a inhibitor, $0.82 \pm 0.02$; $\mathrm{P}<0.05$ (Fig. $3 \mathrm{~B}$ ) Significant differences were also observed in $\mathrm{ESR} \alpha$ protein expression levels: pre-miR-18a, 0.66 \pm 0.02 ; NC, $0.96 \pm 0.01$; miR-18a inhibitor, $1.03 \pm 0.01$; $\mathrm{P}<0.05$ (Fig. 3C). The results of the present study indicated that miR-18a downregulated
ESR $\alpha$ mRNA and protein expression in JEG-3 cells compared with that in control cells.

It has been shown that miRs modulate gene expression through association with the 3'-UTR region of target genes (1-3). A luciferase reporter assay was conducted, and a significant reduction $(0.68 \pm 0.29 ; \mathrm{P}<0.05)$ in luciferase activity was observed in pre-miR-18a-transfected cells, compared with cells in the control groups (NC, 0.98 \pm 0.35 ; mutant control, 0.98 \pm 0.19 ; Fig. 4). The results of the present study suggested that $\mathrm{ESR} \alpha$ is involved in the regulation of miR-18a expression in JEG-3 cells.

\section{Discussion}

Suppression of miR-18a expression leads to decreased cell invasion and increased cell apoptosis in JEG-3 human trophoblast cells, by inducing ESR $\alpha$ expression. The results of the present study supported the findings of Liu et al (9), which demonstrated that miR-18a may suppress ESR $\alpha$ expression in human hepatocellular carcinoma cells.

The JEG-3 cell line is a well-established human trophoblast cell model that has been used in studies investigating failed pregnancies (15-17). In the present study, in vitro experiments were performed in order to determine the effect of miR-18a on JEG-3 cell invasion. The results suggested that the suppression of miR-18a expression may inhibit the invasive capacity of JEG-3 cells. Xu et al (18) demonstrated that overexpression of miR-18a may promote cell invasion in HTR8/SVneo human 
A

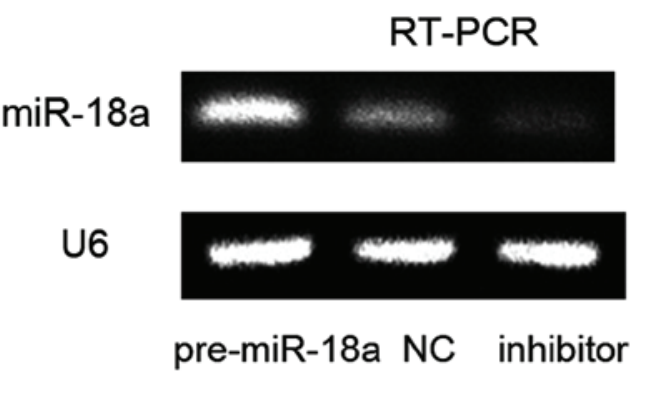

B
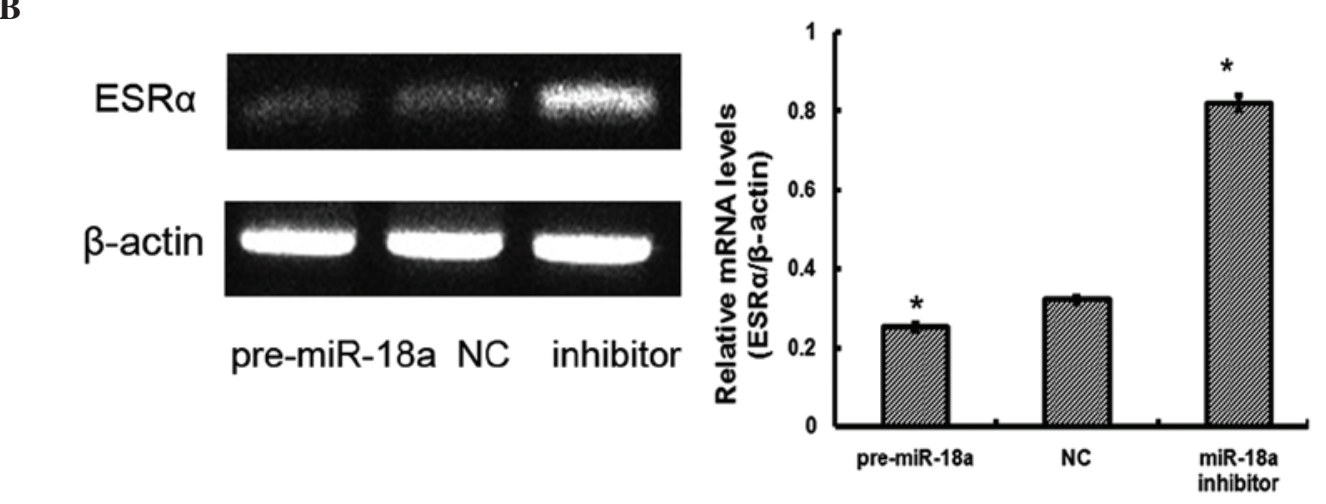

C

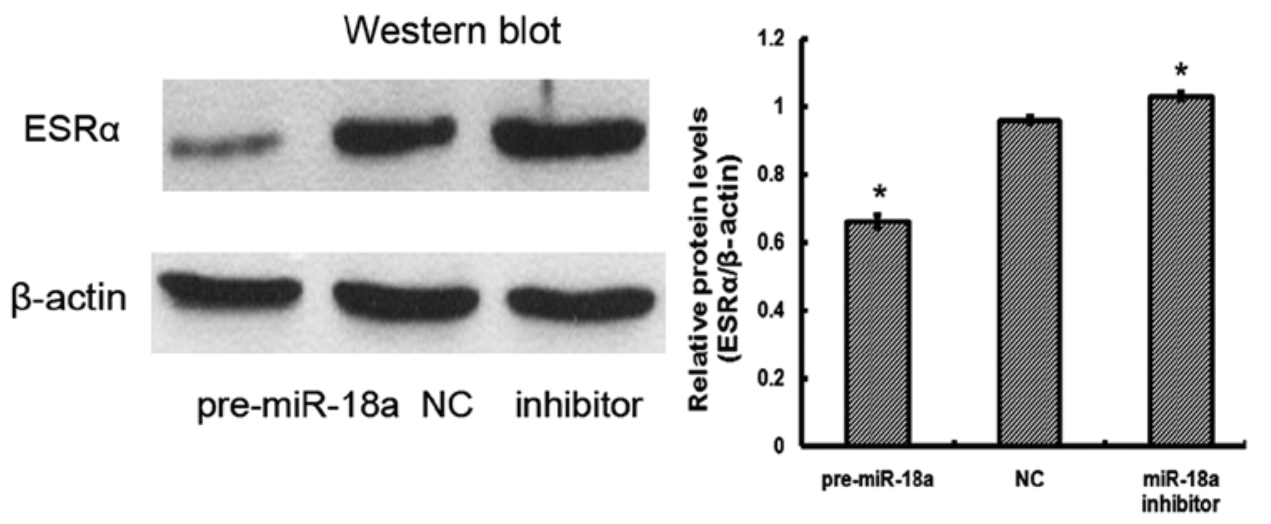

Figure 3. miR-18a suppressed ESR $\alpha$ expression in JEG-3 cells, transfected with miR-18a inhibitor, miR-18a inhibitor FAM control or NC. (A) RT-PCR analysis of miR-18a expression in JEG-3 cells. Human U6 small nuclear RNA was used as an endogenous control. (B) RT-PCR analysis of ESR $\alpha$ mRNA levels in JEG-3 cells, following transfection for $48 \mathrm{~h}$. $\beta$-actin was used as an endogenous control. (C) Western blot analysis of ESR $\alpha$ protein levels in JEG-3 cells following transfection for $72 \mathrm{~h}$. $\beta$-actin was used as internal loading control. Values are presented as the mean \pm standard deviation of three independent experiments. "P<0.05 vs. NC. miR, microRNA; ESR $\alpha$, estrogen receptor $\alpha$; NC, negative control, RT-PCR, reverse transcription-polymerase chain reaction; pre-miR-18a, pre-miR mimic.

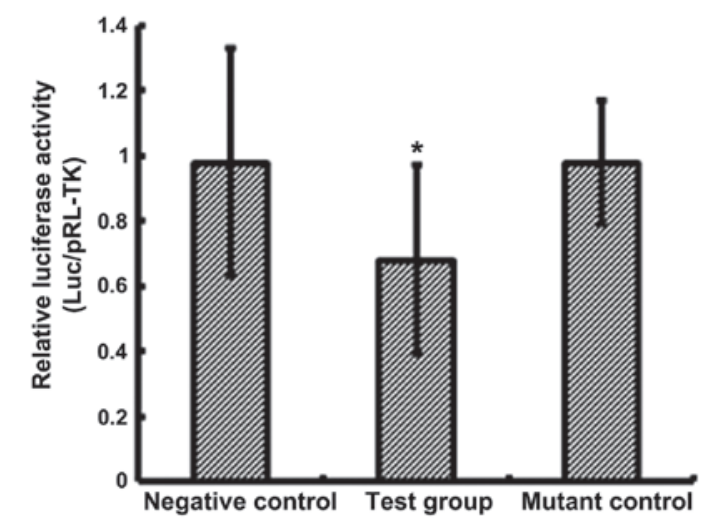

Figure 4. miR-18a interacted with the 3'-UTR of the ESR $\alpha$ mRNA. For the experimental group, JEG-3 cells were transfected with pMIR-UTR and pre-miR-18a. For the negative control group, JEG-3 cells were transfected with pMIR-UTR and pre-miR-control. For the mutant control group, JEG-3 cells were transfected with pMIR-UTR-mutant and pre-miR-18a. Cells were also transfected with $50 \mathrm{ng}$ pRL-TK vector as an internal standard. Values are presented as the mean \pm standard deviation of three independent experiments. "P<0.05 vs. controls. miR, microRNA; Luc, luciferase; ESR $\alpha$, estrogen receptor $\alpha$. 
trophoblast cells by targeting Smad2 expression. Smad2 mediates TGF- $\beta$ signaling, which is involved in regulating trophoblast cell invasion (19-21). Therefore, miR-18a may regulate trophoblast cell invasion via the TGF- $\beta$ signaling pathways. Furthermore, different types of miRs may be involved in the regulation of a single gene (22). Therefore, it will useful to examine other targets of miR-18a in future studies.

The suppression of miR-18a expression led to an increase in JEG-3 cell apoptosis. The results of the present study suggested that miR-18a may function as an antiapoptotic factor in human trophoblast cells. Previous studies have demonstrated that miR-18a is downregulated (8), whilst ESR $\alpha$ expression is upregulated (13), in pre-eclamptic placentas, compared with levels in healthy placentas. The expression of miR-18a was negatively correlated with ESR $\alpha$ expression in pre-eclampsia, which suggests that miR-18a is involved in the pathogenesis of pre-eclampsia, via negative regulation of ESR $\alpha$ expression (8-13). Recent studies have shown that ESR $\alpha$ expression is involved in cell apoptosis (23), and that a change in cell apoptosis is associated with the pathogenesis of pre-eclampsia (24). Therefore, the low expression of miR-18a may affect trophoblast cell apoptosis by regulating ESR $\alpha$ expression, which may contribute to pre-eclampsia. Further investigation is therefore required, in order to clarify the involvement of miR-18a in pre-eclamptic pregnancies.

The results of the present study demonstrated that miR-18a suppressed ESR $\alpha$ expression by targeting its 3'-UTR binding sites. However, ESR $\alpha$ expression was not completely inhibited in response to miR-18a overexpression (Fig. 4). miR-18a gene overexpression led to a decrease in luciferase reporter gene expression by $\sim 30 \%$ (Fig. 4), which suggests that additional miRs may participate in the regulation of ESR $\alpha$ expression. Studies have demonstrated that a single gene may be regulated by a number of different miRs $(1-3,22)$. Therefore, further studies are required, in order to investigate the involvement of other miRs in the regulation of ESR $\alpha$ expression.

In conclusion, the present study demonstrated that miR-18a expression suppresses ESR $\alpha$ expression by targeting binding sites in the 3'-UTR. The suppression of miR-18a led to a decrease in invasion and an increase in the apoptosis of JEG-3 cells. The present study, therefore, provides evidence for the involvement of miR-18a in the pathogenesis of pre-eclampsia.

\section{Acknowledgements}

This study was supported by the Chinese Natural Science Foundation (grant nos. 81471474/31000660 and 81170582), the Postdoctoral Science Foundation of China (grant nos. 2014T70964 and 2013M532203), and Tangdu Hospital Reserve Personnel Fund.

\section{References}

1. Zeng Y: Principles of micro-RNA production and maturation. Oncogene 25: 6156-62, 2006.
2. Lai EC: microRNAs: runts of the genome assert themselves Curr Biol 13: R925-R936. 2003.

3. Ke XS,Liu CM,Liu DP and Liang CC: MicroRNAs: key participants in gene regulatory networks. Curr Opin Chem Biol 7: 516-23, 2003.

4. Bushati N and Cohen SM: microRNA functions. Annu Rev Cell Dev Biol 23:175-205. 2007.

5. Sun BK and Tsao H: Small RNAs in development and disease. J Am Acad Dermatol 59: 725-737, 2008.

6. Barad O, Meiri E, Avniel A, Aharonov R, Barzilai A, Bentwich I, Einav U, Gilad S, Hurban P, Karov Y, et al: MicroRNA expression detected by oligonucleotide microarrays: system establishment and expression profiling in human tissues. Genome Res 14: 2486-2494, 2004

7. Lim LP, Lau NC, Garrett-Engele P, Grimson A, Schelter JM, Castle J, Bartel DP, Linsley PS and Johnson JM: Microarray analysis shows that some microRNAs downregulate large numbers of target mRNAs. Nature 433: 769-773, 2005.

8. Zhu XM, Han T, Sargent IL, Yin GW and Yao YQ: Differential expression profile of microRNAs in human placentas from preeclamptic pregnancies vs normal pregnancies. Am J Obstet Gynecol 200: 661. e1-e7, 2009.

9. Liu WH, Yeh SH, Lu CC, Yu SL, Chen HY, Lin CY, Chen DS and Chen J: MicroRNA-18a prevents estrogen receptor-alpha expression, promoting proliferation of hepatocellular carcinoma cells. Gastroenterology 136(2): 683-693, 2009.

10. Shao W and Brown M: Advances in estrogen receptor biology: prospects for improvements in targeted breast cancer therapy. Breast Cancer Res 6: 39-52, 2004

11. Kuiper GG, Carlsson B, Grandien K, Enmark E, Häggblad J, Nilsson $S$ and Gustafsson JA: Comparison of the ligand binding specificity and transcript tissue distribution of estrogen receptors alpha and beta. Endocrinology 138: 863-870, 1997.

12. Kuiper GG, Enmark E, Pelto-Huikko M, Nilsson S and Gustafsson JA: Cloning of a novel receptor expressed in rat prostate and ovary. Proc Natl Acad Sci USA 93: 5925-5930, 1996.

13. Yin G, Zhu X, Guo C, Yang Y, Han T, Chen L, Yin W, Gao P, Zhang H, Geng J, et al: Differential expression of estradiol and estrogen receptor $\alpha$ in severe preeclamptic pregnancies compared with normal pregnancies. Mol Med Rep 7: 981-985, 2013.

14. Bradford MM: A rapid and sensitive method for the quantitation of microgram quantities of protein utilizing the principle ofproteindye binding. Anal Biochem 72: 248-254, 1976.

15. Kilburn BA, Wang J, Duniec-Dmuchowski ZM, Leach RE, Romero R and Armant DR: Extracellular matrix composition and hypoxia regulate the expression of HLA-G and integrins in a human trophoblast cell line. Biol Reprod 62: 739-747, 2000.

16. Mouillot G, Marcou C, Zidi I, Guillard C, Sangrouber D, Carosella ED and Moreau P: Hypoxia modulates HLA-G gene expression in tumor cells. Hum Immunol 68: 277-285, 2007.

17. Yie SM, Li LH, Li GM, Xiao R and Librach CL: Progesterone enhances HLA-G gene expression in JEG-3 choriocarcinoma cells and human cytotrophoblasts in vitro. Hum Reprod 21: 46-51, 2006.

18. Xu P, Zhao Y, Liu M, Wang Y, Wang H, Li YX, Zhu X, Yao Y, Wang H, Qiao J et al: Variations of microRNAs in human placentas and plasma from preeclamptic pregnancy. Hypertension 63: 1276-1284, 2014.

19. Irving JA and Lala PK: Functional role of cell surface integrins on human trophoblast cell migration: regulation by TGF-beta, IGF-II, and IGFBP-1. Exp Cell Res 217: 419-427, 1995.

20. Morrish DW, Dakour J and Li H: Functional regulation of human trophoblast differentiation. J Reprod Immunol 39: 179-195, 1998.

21. Caniggia I, Grisaru-Gravnosky S, Kuliszewsky M, Post M and Lye SJ: Inhibition of TGF-beta 3 restores the invasive capability of extravillous trophoblasts in preeclamptic pregnancies. J Clin Invest 103: 1641-1650, 1999.

22. Jackson RJ and Standart N: How do microRNAs regulate gene expression? Sci STKE 2007: re1, 2007.

23. Chen P, Wang H, Duan Z, Zou JX, Chen H, He W and Wang J: Estrogen-related receptor alpha confers methotrexate resistance via attenuation of reactive oxygen species production and P53 mediated apoptosis in osteosarcoma cells. Biomed Res Int 2014: 616025, 2014.

24. Levy R: The role of apoptosis in preeclampsia. Isr Med Assoc J 7: 178-181, 2005. 